\title{
A utilização de jogos em treinamentos e ações de institucionalização de processos
}

\author{
Cintya C. Corgosinho Suzuki ${ }^{1}$, Rosana V. Xavier $^{2}$, Priscilla N. Romeu ${ }^{1}$, Lucilia V. \\ Moreira $^{1}$, Renata L. Freitas ${ }^{1}$, Sandra C. Moreira ${ }^{1}$, Pedro Lopes da Rocha Leal Jr. ${ }^{1}$ \\ ${ }^{1}$ Spread Systems - Unidade MSA-Infor \\ R. Andaluzita, 110 - 30.310-030 - Belo Horizonte - MG - Brasil \\ ${ }^{2}$ PPGEE - Programa de Pós-Graduação em Engenharia Elétrica - PUCMG - Pontifícia \\ Universidade Católica de Minas Gerais - Av. Dom José Gaspar, 500 - 30535-901 - \\ Belo Horizonte - MG - Brasil \\ \{cintya, priscilla.neves, lucilia.moreira, renata.freitas, \\ sandra.moreira, pedro\}@spread.com.br, rosanavx@gmail.com
}

Resumo. A capacitação dos profissionais e a realização de treinamentos com foco nos processos organizacionais são de suma importância na caminhada para alcançar maturidade no gerenciamento e desenvolvimento de software. Este artigo descreve a experiência, os pontos positivos e as lições aprendidas pela Spread Systems - Unidade MSA Infor - ao utilizar jogos, como o RPG (Role Playing Game), para auxiliar na institucionalização dos processos. A experiência ocorreu durante o programa de implantação do CMMI nível 5 e foi essencial para o sucesso da organização na avaliação, garantindo maior envolvimento entre as pessoas e a disseminação do conhecimento com criatividade e fácil aprendizado.

Abstract. The professional's preparation and training sessions focused on organizational processes are extremely important in the journey to reach maturity in management and software development. This article describes the experience, strengths and lessons learned by the Spread Systems-MSA Infor Unit - using games such as RPG (Role Playing Game), to assist in the institutionalization of processes. The experiment happened during the implementation program of CMMI level 5 and was essential in the success of the organization in the assignment, ensuring greater engagement between people and dissemination of knowledge with creativity and easy learning.

\section{Contextualização}

A qualidade de software é sustentada por três pilares que são dimensões críticas em que uma organização que deseja melhorar seu desempenho em desenvolvimento e manutenção de produtos e serviços de qualidade deve se concentrar: pessoas, processos e tecnologia [Chrissis 2007].

Segundo Curtis (1995), tradicionalmente, as organizações enfatizam processos ou tecnologia, e não o elemento pessoas. A maturidade de uma empresa em todas as tarefas essenciais ao sucesso de um projeto deve ter foco nos três componentes interrelacionados, exigindo melhoria contínua de pessoas e condições para o seu desempenho. 
A partir da premissa de gerenciamento de processos promovida pelo SEI (Software Engineering Institute), onde "a qualidade de um sistema ou produto está diretamente relacionada à qualidade do processo utilizado para desenvolver ou mantêlo", o adequado estabelecimento, execução e suporte ao processo fazem-se necessários. O processo, por sua vez mostra-se dependente da capacitação, comprometimento e ainda, da motivação por parte das pessoas envolvidas. Considerados os aspectos, fatores como capacitação adequada, a garantia de comprometimento para com as funções, aliados a motivação, destacam-se quanto à relevância em uma organização focada em melhoria contínua.

Citada em produção científica de diferentes áreas, a utilização de formas lúdicas de aprendizado, como os jogos, mostra-se eficiente ferramenta auxiliar em atividades de motivação e ensino. Para Grando (1995), o jogo desencadeia o processo de construção dos conceitos matemáticos de forma lúdica, dinâmica, desafiadora e motivadora. Nagamatsu et al. (2006) destacam que jogos de simulação dos processos de uma organização podem aumentar a capacidade dos participantes em visualizar o todo, com aprimoramento do pensamento estratégico e da interpretação de cenários e situações. Segundo Piaget (1993), os jogos consistem em assimilação funcional, num exercício das ações individuais já aprendidas gerando, ainda, um sentimento de prazer pela ação lúdica em si e pelo domínio sobre as ações.

Um tipo de jogo caracterizado por permitir ações individuais e que surgiu nos EUA em 1974 é o RPG (Role Playing Game) ou "Jogo de Representação". Os participantes interpretam papéis pré-estabelecidos e se envolvem em narrativas escritas por um "mestre". A função do mestre é apresentar ao grupo de jogadores uma história que contenha enigmas e situações que exigirão escolhas por parte dos jogadores. Estes, por sua vez, controlam personagens que vivenciarão a história, discutindo entre si as escolhas que farão e as soluções que darão aos problemas que surgirem. É comum a utilização de dados de diversas faces para decidir na sorte determinados rumos da narrativa [Marcatto 1996].

Este artigo relata a experiência da Spread Systems - Unidade MSA-Infor em utilizar o RPG como estratégia de treinamento com foco na institucionalização dos processos relacionados ao alto nível de maturidade, transmitindo conhecimentos e aumentando a motivação e integração dos seus colaboradores.

O artigo está estruturado em três sessões, além desta contextualização. A sessão 2 apresenta a identificação da necessidade de intensificação de treinamentos e motivação para adoção do formato de jogos RPG. Prossegue-se com a estruturação e realização dos jogos, pontuação e divulgação dos resultados. Os resultados obtidos e a conclusão são apresentados nas seções 3 e 4 respectivamente.

\section{Descrição da Experiência}

\subsection{A estruturação dos jogos}

A Spread Systems - Unidade MSA-Infor, organização que apresenta um histórico em investimentos em melhoria de processos, iniciou em 2009 um ciclo de melhorias para obtenção do nível 5 do CMMI. Diante da complexidade dos termos e conceitos relacionados ao alto nível de maturidade, uma das primeiras percepções do grupo foi 
quanto à necessidade de intensificação dos treinamentos nos processos e assuntos relacionados.

Em face desta necessidade, discutiu-se em reunião do SEPG (Software Engineering Process Group), grupo responsável por avaliar, apresentar e implantar novos métodos e tecnologias na organização e tratado como Engineering Process Group (EPG) no modelo CMMI [Chrissis 2007], a melhor estratégia para treinamento dos colaboradores. Em consulta ao banco de lições organizacionais, observou-se o registro de que treinamentos anteriores sob o formato de gincana destacaram-se em eficácia em relação ao demais. Baseando-se nesta constatação, visando o envolvimento e capacitação de toda a organização, estabeleceu-se o formato de gincana como estratégia de treinamentos para o ciclo, e a área de Gestão da Qualidade como responsável por tal.

A gincana teve duração de cinco semanas e seguia um formato de reuniões presenciais com cada equipe, nas quais um membro do GDQ conduzia um jogo de perguntas e respostas. As perguntas eram diretas, sorteadas para cada um dos membros da equipe, não obedeciam a uma ordem cronológica e tratavam de pontos específicos do processo. Exemplo de perguntas utilizadas: "De que forma é feita seleção da solução técnica que melhor satisfaz aos critérios definidos?" Ou ainda: "Como são calculadas as estimativas do projeto?" A resposta era avaliada e classificada como: correta e completa, correta e incompleta, e incorreta, levando em consideração o conteúdo dos processos. Ao final de cada sessão, os pontos eram totalizados e divulgados nos quadros de aviso da empresa. As equipes eram divididas de acordo com as funções executadas (programadores, gerentes de projeto, analistas, dentre outras).

O objetivo de promover envolvimento efetivo demonstrou-se alcançado, acompanhado de clima saudável de competição entre os envolvidos. Entretanto, a utilização do formato de perguntas e respostas diretas provocou em alguns participantes a sensação de relativa pressão no momento da resposta e ainda, a vitória do grupo "Gerentes de Projeto", colocou em questão a adequada divisão das equipes, pontos observados por alguns dos participantes.

Utilizando-se dos feedbacks recebidos, o formato dos jogos de gincana foi aprimorado. Ao realizar pesquisas sobre a utilização de jogos na educação, idealizou-se, para a nova fase de treinamentos, a utilização do RPG (Role Playing Game), tendo em vista a dinâmica que este jogo proporciona. Vale ressaltar que experiências com a utilização dos jogos RPG como tecnologia educacional tem sido relatadas nos cadernos e guias do Ministério da Educação no Brasil [MEC 2006].

Foi necessária a adaptação do formato dos jogos RPG para viabilizar a sua realização na empresa. As histórias foram escritas por membros da equipe GDQ (Gestão da Qualidade) e simulavam o ciclo de vida de um projeto. As equipes foram estabelecidas considerando os grupos de trabalho de cada projeto de desenvolvimento de software, compostas por um gerente de projeto, um gestor de ambiente, um gestor de configuração, desenvolvedores, entre outras funções. A definição dos papéis considerou a função atual que cada profissional desempenhava nos projetos. Um membro da GDQ foi designado para conduzir as sessões, este no papel de narrador-mestre. A utilização dos dados foi limitada a alguns pontos da história, contemplando alguma dica para a situação ou duração extra para alguma atividade a ser cumprida. 


\subsection{A escrita das histórias}

As histórias foram escritas com o objetivo de relatar o dia a dia de um projeto, as interações entre os seus componentes para a execução do trabalho e solução de situações de conflito. Para tanto, o desafio consistiu em distribuir o conteúdo dos processos em uma história seqüencial e envolvente, abrangendo situações corriqueiras e problemas sobre os quais os participantes seriam direcionados a interagir, interpretar e apresentar as soluções. Foram escritas cinco sessões, com o conteúdo organizado conforme demonstrado no Quadro 1.

\section{Quadro 1. Divisão dos assuntos abordados nas sessões dos jogos de RPG}

\begin{tabular}{|l|l|}
\hline Sessões & Assuntos abordados \\
\hline Sessão 1 & $\begin{array}{l}\text { Início do projeto: designação do gerente de projeto, planejamento, estimativas, montagem da } \\
\text { equipe de trabalho, customização de processo, gestão de ambiente e configuração, reunião de } \\
\text { abertura, levantamento requisitos, utilização de ferramentas relacionadas. }\end{array}$ \\
\hline Sessão 2 & $\begin{array}{l}\text { Especificação e acompanhamento do projeto: especificação de casos de uso, projeto e } \\
\text { arquitetura, rastreabilidade, acompanhamento de riscos, revisões, aprovação/validação dos } \\
\text { requisitos, protótipo, entrega intermediária, auditoria de linha de base, fluxo para tratamento } \\
\text { de uma inovação sugerida pela equipe. }\end{array}$ \\
\hline Sessão 3 & $\begin{array}{l}\text { Implementação e acompanhamento do projeto: codificação, testes unitários, projeto dos } \\
\text { testes, inspeção de código, integração, controle de alteração, feedback sobre a utilização do } \\
\text { processo, conflitos e negociação de recursos, acompanhamento de prazos, dependências. }\end{array}$ \\
\hline Sessão 4 & $\begin{array}{l}\text { Primeira entrega e acompanhamento do projeto: execução dos testes, documentação, } \\
\text { validação pelo cliente, controle dos erros encontrados, coleta de aceite, coleta e análise de } \\
\text { métricas, verificação da efetividade dos treinamentos da equipe, decisão formal. }\end{array}$ \\
\hline Sessão 5 & $\begin{array}{l}\text { Encerramento do projeto: reunião de análise crítica, auditoria da qualidade, tratamento de } \\
\text { não conformidades e encerramento, aceite final, pesquisa de satisfação, liberação de } \\
\text { recursos, coleta de lições, alimentação dos bancos organizacionais. }\end{array}$ \\
\hline
\end{tabular}

Como a organização possui três processos-padrões, direcionados para o tipo de ciclo de vida dos projetos (ciclo completo, manutenção e fábrica de software), foi elaborada uma história focada no ciclo completo e, em seguida, customizações foram realizadas para que, em cada sessão, a história representasse a realidade de trabalho de cada uma das equipes e facilitasse a assimilação do conteúdo. Para as equipes de ciclo completo a história tinha início com um novo contrato e a reunião de abertura de um novo projeto. Já para equipes de manutenção, a história foi adaptada para iniciar com solicitações do cliente (evolutivas e corretivas) para a próxima versão do produto de software.

No conteúdo das histórias, além das atividades novas e que precisavam ser institucionalizadas, foram incluídas atividades polêmicas na organização que, ao serem vivenciadas em todo o seu contexto poderiam ser discutidas entre os participantes e esclarecidas. A história era composta de sentenças narrativas que culminavam em situações onde os personagens deveriam atuar, simulando a atividade ou momento do projeto solicitado. Para viabilizar a pontuação da equipe ao se deparar com cada situação ou momento de decisão, foram definidas pelo GDQ palavras-chave que, se mencionadas pelos participantes em suas atuações, contabilizariam pontos para a equipe (expressões em negrito na Figura 1). Também foram selecionados termos que indicavam respostas corretas e superiores às expectativas, ou seja, representavam partes do processo relevantes para a situação, mas não essenciais para desempenho da ação (palavras sublinhadas e em negrito na Figura 1). 
1) Narrador: Você <GERENTE DE PROJETO> solicitou à gerência sênior recursos para o projeto. Depois de verificar o pool de recursos disponiveis, os seguintes profissionais foram designados para o seu projeto: $\angle F A L A R O N O M E$ DE QUEM ESTÁ NA SALA>. Comunique, por favor, ao pessoal que eles estẫo no projeto $e$ simule a reunião de nivelamento!

O Gerente de projeto deve simular a reunião de nivelamento. Deve informar aos presentes que farão parte do projeto, explicar o projeto e seu contexto, bem como os objetivos para o trabalho da equipe no que diz respeito à fase/iteração que está sendo iniciada. Apresentar o cronograma e solicitar comprometimento. Verificar se há algum empecilho. Bônus: convidar algum membro da equipe da qualidade para a reunião.

2) Narrador: $O$ gerente perguntou se vocês entenderam e se estavam de acordo com os prazos e esforço das atividades... Você <ESCOLHER UM PARTICIPANTE> VIU que um dos casos de uso do projeto era muito complexo e que o tempo para especificação / desenvolvimento estava muito abaixo do que você esperava... O que você faz?

Negociação de prazos com ogerente utilizando justificativas embasadas para ser possível o comprometimento com o cronograma.

3)Narrador: Acabou a reunião de nivelamento! Vocês foram para seus lugares e algum colega comentou que uma pessoa pode assumir mais de um papel na equipe. Você <ESCOLHER UM PARTICIPANTE $>$ ficou confuso sobre quais seriam os seus papéis... Esclareça sua dúvida!

Deve abrir o plano do projeto em que trabalha atualmente e verificar se está preenchido com os papéis que desempenha.

Figura 1. Parte do conteúdo da história de uma sessão, utilizada pelo narrador

As sessões foram planejadas para ter a duração de aproximadamente 2 horas. A programação das sessões considerava as restrições de agenda das equipes, evitando ausências que afetassem o desempenho do grupo.

\subsection{A realização dos jogos}

Considerando as características do formato RPG e objetivo de sua utilização como forma de treinamento, a proposta do jogo consistia na inserção dos participantes em um cenário fictício e na verificação do desenvolvimento destas pessoas perante as diversas situações do cotidiano de um projeto.

O roteiro para realização de uma sessão está representado na Figura 2, a seguir:

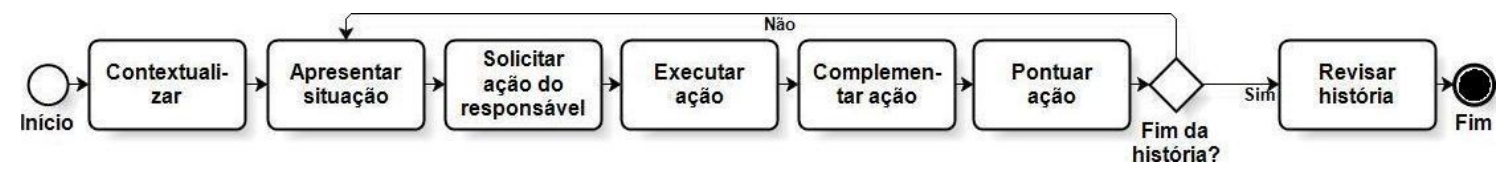

Figura 2. Roteiro para realização de uma sessão

As sessões de jogos tinham início com o representante do GDQ no papel de narrador-mestre, contextualizando os participantes sobre a fase e momento no qual o projeto fictício se encontrava. Em seguida, era apresentada uma nova situação para a equipe e, ao membro que atuava na função relacionada, era solicitada uma ação para resolver o problema. Todos os participantes observavam a execução da ação, constituindo uma oportunidade para conhecimento em detalhes, das responsabilidades e funções daquele papel e, caso necessário, poderiam complementá-la. Como normalmente o gerente de projetos detinha o conhecimento de todo o processo organizacional, priorizava-se a participação das demais pessoas no complemento das ações. Em seguida, o narrador-mestre identificava quais palavras (chave e bônus) 
haviam sido mencionadas durante a ação, registrando-as na planilha de pontuação. Ao final de cada sessão, em caráter de nivelamento, o narrador-mestre repassava toda a história à equipe, esclarecendo aos participantes assuntos relacionados às palavraschaves e bônus não mencionados.

Também foram promovidas algumas "missões" para as equipes, tais como: revisão de um caso de uso por um integrante de cada uma das equipes, prova sobre conhecimentos gerais - baseados nos processos, e outras atividades interativas, como a escolha de um nome que represente a equipe, etc. Cada missão cumprida com sucesso correspondia a pontos extras, o que fazia com que o jogo ficasse mais competitivo e desafiante.

É importante ressaltar que características como clareza, criatividade, domínio do processo, capacidade de improviso, foram fundamentais para que o narrador-mestre conduzisse as sessões, visto que cada sessão diferenciava da anterior pelas ações e reações de cada equipe. Com a equipe GDQ envolvida nas demais atividades do ciclo de melhorias, somente um representante foi designado para conduzir as sessões, realizadas com cada equipe em horários distintos. Foi fundamental a colaboração dos participantes quanto ao sigilo sobre o conteúdo de cada sessão, evitando a preparação das equipes adversárias para o jogo, e, assim, sendo possível visualizar as reações espontâneas de cada profissional, os pontos do processo que estavam institucionalizados e os que necessitavam de reforço. Ao final de uma rodada de sessões, as equipes discutiam entre si atitudes tomadas em relação aos problemas apresentados, os artefatos citados e os esquecidos, contribuindo para a disseminação do conhecimento e levantamento de diferentes pontos de vista.

\subsection{A pontuação e divulgação dos resultados}

A contabilização dos pontos era realizada pelo narrador-mestre. Cada palavra-chave citada recebia uma pontuação, que variava de acordo com a sua relevância e peso atribuído. Para cada sessão, os pontos e os bônus de cada equipe eram somados e divulgados. Foi adotada a periodicidade semanal para divulgação dos resultados, estes publicados nos murais da empresa. A expectativa pelos resultados era intensa e, logo após a fixação do informativo, grande parte da equipe se deslocava até os quadros de avisos para conferir o ranking.

Foi realizado um esforço maior que o estimado para a distribuição e contabilização dos pontos do jogo. Como as demais atividades da equipe GDQ para implantação dos níveis 4 e 5 do CMMI na empresa eram prioritárias, não houve um planejamento detalhado para a distribuição dos pontos, sendo necessário, em alguns momentos, rever a forma com que os pontos seriam distribuídos para que a competição ficasse acirrada até a última sessão e para que os assuntos mais relevantes tivessem peso adequado.

Em alguns momentos a composição das equipes também interferiu na pontuação. Para evitar que a desmotivação com uma pontuação muito inferior aos demais, buscou-se montar equipes homogêneas, distribuindo, por exemplo, os recursos novatos na empresa entre as equipes, para que tivessem a chance de aprender com os mais experientes e, ao mesmo tempo, não prejudicassem uma determinada equipe. A substituição de um recurso que desempenhava um papel único na equipe não foi 
prevista e, quando houve necessidade, a gerência sênior foi convocada para tal, substituindo-o nos jogos.

\section{Resultados Obtidos}

A utilização dos jogos como estratégia de treinamento proporcionou benefícios à organização e aos próprios colaboradores. Percebeu-se maior motivação para os treinamentos, desenvolvimento da capacidade de trabalhar em equipe, disseminação do conhecimento quanto aos processos organizacionais e um ambiente de trabalho colaborativo. A premiação, mesmo que simbólica oferecida ao final de cada gincana demonstrou-se importante na manutenção do clima competitivo entre as equipes, e não entre pessoas.

Com a utilização de histórias no formato RPG, os colaboradores vivenciaram o fluxo completo do processo da organização, incluindo as entradas e saídas de cada uma das atividades, mesmo as de responsabilidade de outras funções. Garantir a ciência das pessoas quanto à importância de todas as suas atividades foi essencial para quebrar paradigmas e promover um maior comprometimento de cada um dos colaboradores. Para o grupo GDQ foi possível avaliar o conhecimento de cada participante em relação ao processo e identificar melhorias em artefatos e atividades e direcionar a atuação das auditorias.

Não fez parte dos objetivos da organização apurar o investimento realizado em treinamentos, não existindo assim medidas objetivas que comprovem a eficácia da técnica utilizada. Apesar disso, os dados coletados apontam para um melhor aproveitamento do formato RPG em comparação com os formatos utilizados no período de obtenção do nível 3 do CMMI. A aplicação de provas para medição dos conhecimentos foi realizada em ambos os ciclos. No ciclo referente à obtenção do nível 3 , obteve-se média de $66 \%$ de aproveitamento, enquanto que, no ciclo referente ao nível 5 , após realização dos jogos, a média foi de $75 \%$ de aproveitamento. Considerando que as provas eram semelhantes em relação aos níveis 2 e 3 do modelo, que houve incremento com questões relacionadas aos níveis 4 e 5 , e que apenas $14 \%$ dos profissionais participaram do ciclo anterior, há indícios de que a forma utilizada no último ciclo facilita a assimilação de conteúdo. Em relação ao esforço, foram apuradas 2.250 horas no estilo anterior de treinamento utilizado na organização para a obtenção do nível 3, envolvendo 40 pessoas, e, no ciclo referente ao nível 5, 1.700 horas do estilo dos jogos, envolvendo 70 pessoas. Apesar da possibilidade de existirem outras variáveis não apuradas que provavelmente interferem neste resultado, esta redução pode indicar que, com menos esforço e, consequentemente menos custo, é possível atingir os mesmos objetivos e aumentar a motivação dos colaboradores.

\section{Conclusões}

O treinamento é parte fundamental de um programa de melhoria de processos. A experiência da Spread Systems mostrou que a utilização de jogos de interpretação como estratégia de treinamento pode trazer benefícios para a organização e facilitar a institucionalização e a disseminação do conhecimento. Entretanto, a estrutura para treinamentos deste tipo deve ser planejada desde o início do ciclo de melhorias, já que a escrita das histórias e a decisão sobre forma de pontuação e premiação demandam um 
esforço significativo da área responsável. A indefinição de regras de pontuação e premiação pode gerar conflitos que, em casos mais extremos de competitividade e imaturidade dos envolvidos, podem atrapalhar o alcance dos objetivos.

Através das discussões promovidas pelos jogos, foi possível identificar oportunidades de melhoria nos processos, problemas recorrentes quanto ao uso dos artefatos, e dúvidas ainda existentes em relação aos novos conceitos. O momento do treinamento tornou-se mais um canal aberto de comunicação entre um representante da área da qualidade, e os usuários dos processos organizacionais.

Ao disseminar o conhecimento de forma criativa, percebeu-se maior assimilação de conteúdo e segurança dos envolvidos em relação às suas atividades, garantindo a institucionalização do processo com maturidade nível 5 e o comprometimento de todos com o objetivo final.

\section{Referências}

Chrissis, M.B., Konrad, M. e Shrum, S. (2007) "CMMI: guidelines for process integration and product improvement". Addison-Wesley.

Curtis, B., Hefley, W.E., Miller, S. (1995) "Overview of the People Capability Maturity Model", Pittsburg.

Grando, R. C. (1995) “O jogo e suas possibilidades metodológicas no processo de ensino-aprendizagem da matemática”. Dissertação de Mestrado da Faculdade de Educação da UNICAMP, Campinas-SP. Disponível em: http://cutter.unicamp.br/document/?code=vtls000084233. Acesso em 13 de abril de 2011.

Marcatto, A. (1996) "Saindo do Quadro: Uma Metodologia Educacional Lúdica e Participativa baseada no Role Playing Game". Exata Comunicação e Serviços S/C LTDA, São Paulo.

MEC. Ministério da Educação (2006) "Cadernos Temáticos". Disponível em $<$ portal.mec.gov.br/setec/arquivos/pdf/cadernos09_v2.pdf $>$. Acesso em 08 de março de 2011.

Nagamatsu, F. A. et al (2006). "A Aplicação do Jogo de Empresas no Desenvolvimento Gerencial: Um Estudo Aplicado em Cursos de Graduação e de Pós-Graduação (Nível Lato Sensu)". In: IX Seminários de Administração FEA-USP, São Paulo - SP, Brasil. Disponível em: <http://www.ead.fea.usp.br/semead/9semead/>. Acesso em: 11 de abril de 2011.

Piaget, J. (1993) “Seis Estudos de Psicologia”. Forense Universitária, Rio de Janeiro. 